\title{
Bad Bunny y Bach: mitos e imaginarios culturales*
}

[Artículos]

Francisco Castillo García**

Recibido: 6 de abril de 2021

Aprobado: 25 de junio de 2021

Citar como:

Castillo, F. (2021). Bad Bunny y Bach: mitos e imaginarios culturales. Análisis, 53(99). https://doi.org/10.15332/21459169.6498

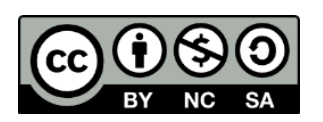

\section{Resumen}

Este artículo explora la noción de mito e imaginario colectivo según se manifiestan en las figuras de Bad Bunny (1994-) y de Johann Sebastian Bach (1685-1750). Bad Bunny ha sido identificado como el depositario de un imaginario que sitúa al reggaetón como un género musical que marca la decadencia moral de la cultura. Bach, por el contrario, encabeza el canon de compositores que hacen de la música clásica un paradigma de arte musical culto y elaborado. La reflexión sugiere que ambas representaciones son parte de una mitología que esconde problemáticas complejas como discriminación de clase y hegemonías culturales violentas. Las conclusiones señalan la desmitificación de ambos músicos como una estrategia para, no solo apreciar de manera más equilibrada su

${ }^{*}$ Artículo de reflexión.

** Magister en Estudios Artísticos. Facultad de Artes ASAB. Universidad Distrital. Correo electrónico: fjcastillog@udistrital.edu.co; ORCID: https://orcid.org/0000-0002-3897-8050 
música, sino para atender problemáticas sociales sin los fanatismos que ambas comunidades musicales promueven en sus mitos.

Palabras clave: Bach, Bad Bunny, Mito, Reggaetón, Música Clásica.

\section{Bad Bunny and Bach: Cultural Myths and Imaginaries}

\section{Abstract}

This paper explores the notion of myth and social imaginary as manifested in the figures of Bad Bunny (1994- ) and Johann Sebastian Bach (1685-1750). Bad Bunny has been identified as the depositary of an imaginary that puts reggaeton as a musical genre that marks the moral decadence of the culture. Bach, by contrast, leads the canon of composers who make classical music a paradigm of cultured and elaborate musical art. The reflection suggests that both representations are part of a mythology that hides complex issues such as class discrimination and violent cultural hegemonies. The conclusions point to the demystification of both musicians as a strategy to not only appreciate their music in a more balanced way, but also to address social issues without the fanaticism that both musical communities promote in their myths.

Keywords: Bach, Bad Bunny, Myth, Reggaeton, Classical Music.

\section{Bad Bunny e Bach: mitos e imaginários culturais}

\section{Resumo}

Este artigo explora a noção de mito e o imaginário coletivo manifestados nas figuras de Bad Bunny (1994-) e Johann Sebastian Bach (1685-1750). Bad Bunny foi identificado como o depositário de um imaginário que coloca o reggaetón como um gênero musical que marca o declínio moral da cultura. Bach, ao contrário, lidera o cânone de compositores que fazem da música clássica um paradigma da arte musical culta e elaborada. A reflexão sugere que ambas as representações fazem parte de 
uma mitologia que esconde problemas complexos, como discriminação de classe e hegemonias culturais violentas. As conclusões apontam para a desmistificação de ambos os músicos como estratégia para não só valorizar sua música de forma mais equilibrada, mas também para enfrentar os problemas sociais sem o fanatismo que ambas as comunidades musicais promovem em seus mitos.

Palavras-chave: Bach, Bad Bunny, Mito, Reggaetón, Música Clássica.

\section{Introducción}

En el 2020 tuve a mi cargo dos seminarios electivos como parte de las actividades que realizamos los profesores universitarios. Uno de ellos se llamaba Reggaetón y crítica musical, y el otro Vida y obra de J.S. Bach. Si bien ambos espacios académicos fueron formulados desde la Facultad de Artes, asistieron estudiantes de diferentes disciplinas. A las pocas semanas de clase, empecé a percibir que ambas materias se estaban haciendo muy similares, y en el diálogo con los estudiantes de uno u otro seminario me sorprendí a mí mismo reciclando comentarios, ejemplos y respuestas de una clase en la otra. Como nada de eso fue planeado, ni las clases fueron diseñadas con ninguna intersección en mente, se despertó una curiosidad por entender qué explicaba dicha situación. Evidentemente, las similitudes entre música barroca y reggaetón no están en la superficie de las cualidades musicales, lo cierto es que, en las clases que dicté, Bach y Bad Bunny compartían el hecho de ser objetos de un imaginario muy presente en las voces de los estudiantes.

La aproximación a la vida y obra de Johann Sebastian Bach que fue propuesta en clase, contrastó con la visión un tanto endiosada que compartían los estudiantes. No en pocas ocasiones se referían a Bach como "el padre de la música", "el padre de la armonía” e "inventor de los sostenidos y bemoles", junto con otra serie de miradas que reverencian a Bach como un músico absolutamente extraordinario, fuera de todo 
concurso y casi separado del mundo terrenal. Por otro lado, la aproximación a Bad Bunny y al reggaetón que fue propuesta en clase, contrastó con una visión un tanto apocalíptica sobre el género, un agente peligroso para la moral de los jóvenes, un conjunto de letras denigrantes y de bailes hipersexualizados en un contexto que denigra del arte musical por ser "solamente un producto comercial". En tanto profesor de estos espacios académicos, y considerando que yo no comparto esas posiciones, supuse que podría ser solo un asunto de falta de información. No obstante, rápidamente y después de algunas exposiciones de mi parte, noté que la resistencia a revisar críticamente esos imaginarios tenía unos anclajes más profundos y, por ende, requerían una revisión más aguda.

Bach es uno de los compositores que integran el canon de la música clásica occidental. Como parte de un proyecto cultural y político que tiene muchísimos años, esta música fue una de las banderas del eurocentrismo que gobernó de manera transversal el pensamiento occidental durante siglos, en un proceso que no es necesario detallar aquí. Judith Becker (1986) logró sintetizar las razones que fueron esgrimidas para defender la tesis según la cual la música clásica era vista como la mejor música del mundo: (1) cubrir un espectro amplio de emociones, (2) gozar de altísima complejidad técnica y (3) estar sintonizada con un orden natural. Se valora entonces que las composiciones sean capaces de proyectar pasiones diversas y contrastantes ${ }^{1}$, al tiempo que refuercen la idea del compositorgenio $^{2}$ y que las leyes que definen su proceso creativo descansen en leyes naturales, inmutables y sagradas 3 . Si la música clásica centro europea ha

\footnotetext{
${ }^{1}$ Al punto de configurar aparatos teóricos que les permitieran controlar las emociones con precisión. Ver López Cano (2000).

${ }^{2}$ Como bien lo resaltan las biografías escritas sobre dichos músicos (Wiley, 2015).

Adicionalmente, no es casual que estos genios sean siempre hombres-blancos.

${ }^{3}$ La naturaleza como argumento legitimador no es, de ninguna manera, exclusiva de la historia de la música occidental. Se convoca también la naturaleza en discusiones sobre tauromaquia, aborto y veganismo. Para el caso musical, cabe recordar el texto de Clark y Rehding (2001).
} 
sido objeto de tal valoración positiva, enmarcada en colonialismos y poscolonialismos, Bach ocupa un lugar privilegiado en dicho canon. Dado que sujetos famosos como Beethoven, Mozart, Chopin o Liszt manifestaron su devoción hacia Bach, este fue convertido por la historiografía en el centro de toda perfección musical. Manifestaciones de este fenómeno se encuentra por doquier: programas de formación profesional en música dan muchísima atención a sus composiciones, se pide explícitamente tocar Bach en concursos para ocupar plazas en las orquestas y se le atribuyen incluso beneficios extramusicales4.

Bad Bunny y el reggaetón han sido ubicados en la orilla opuesta. Tanto el discurso académico convencional como el imaginario colectivo han sido proclives a situarlo como prácticas que amenazan la moral de los jóvenes (Penagos, 2012). Sus letras han sido calificadas por Martínez (2014) como sexistas, amén de las imágenes ahí reforzadas: violencia, asimetrías de género, rol masculino dominante y femenino pasivo. El perreo en De Toro (2011) es un baile que reduce a la mujer a la condición de objeto animalizado y descalificado. Siguiendo el argumento de Becker antes mencionado, el rango de emociones contenidas en una canción de reggaetón no llega a los talones de lo que acontece en una cantata de Bach, sus complejidades técnicas son incomparables y la teoría musical que soporta las canciones de Bad Bunny no reflejan la estructura perfecta del orden natural.

¿Qué tienen entonces en común Bad Bunny y Bach? que sobre ambos personajes opera fuertemente un imaginario que no soporta un análisis crítico. Tanto la superioridad imaginada de Bach por encima de todos los

\footnotetext{
${ }_{4}^{4}$ Por ejemplo, Pedrosa (2012) lo presenta como aporte potencial al desarrollo del liderazgo empresarial, y Ardila (2009) lo identifica como la solución al debate entre el teísmo y el ateísmo.
} 
demás músicos, como la amenaza peligrosa que constituye la imagen de Bad Bunny para la sociedad son mitos.

\section{Bad Bunny y Bach en tanto mitos}

Desde hace muchos años, la idea del mito ha sido tema de estudio y análisis en campos diversos de las humanidades. Roland Barthes sentó las bases de una aproximación al mito como herramienta para leer en clave crítica aspectos diversos de la cultura. El autor define mito como "un habla, no un objeto ni un concepto ni una idea, se trata de un modo de significación" (Barthes, 1999, p. 108). Desde ahí notó que la cultura está plagada de mitos visibles en la primera sección de su texto Mitologías, en el cual aborda temas tan dispares como el cerebro de Einstein, la lucha libre, la carne asada con papas a la francesa, los juguetes y la astrología. Para poder asumir que el concepto del mito tiene extensiones tan disímiles, hay que tener en cuenta que el término tiene dos definiciones básicas, ambas relacionadas y además consecuentes en la lista de acepciones que descansan en el diccionario de la RAE.

Por un lado, los mitos son narraciones antiguas llenas de significados y simbolismos. En ese sentido, el término es empleado por autores como Eliade (1968), Campbell (1991), Asimov (1981) y muchos otros. Abundan en las librerías recopilaciones de mitos griegos, chinos, americanos y de otras tradiciones culturales, usualmente en la sección de antropología o historia. Estos relatos no tienen una forma única, ya que la oralidad fue su medio principal de transmisión. Los acontecimientos ahí relatados guardan simbolismos profundos, explicaciones del origen de algún elemento o fenómeno natural, y representan estructuras que expresan también jerarquías sociales o modelos de conducta cultural.

Por otro lado, también se entiende como mito aquello que, siendo falso, es considerado verdadero por muchas personas. En ese sentido, el término se 
usa en textos como Siete mitos de la conquista española (Restall, 2004), El mito del capitalismo (Tepper, 2020) o El mito de la Derecha (Bueno, 2008). Junto a estos, se posa una plétora de textos en los que se revisa críticamente una creencia popular que resulta falaz en la voz del autor y que merece una desmitificación para, con ello, comprender de manera más equilibrada el asunto.

Max Horkheimer y Theodor Adorno explican en la Dialéctica de la Ilustración que dicha ambigüedad semántica tiene profundas raíces históricas: "Los dioses del pasado encarnaban la naturaleza como poder universal. La ilustración ve en ellos una crónica superficial de tensiones y choques entre elementos diversos, que al establecerse como ciencia redujo los mitos a creaciones de la fantasía" (Horkheimer y Adorno, 1998, p. 72). Entonces es claro que una mirada científica y positivista del mundo, solo vería en los mitos antiguos narraciones equivocadas e insuficientes para explicar los truenos o el arcoíris, de manera que tal enfoque los redujo a ser historias ficticias que esperan ser iluminadas con las herramientas provistas por la ilustración.

Tanto Bad Bunny como Bach son mitos, pero cada uno de ellos se enmarca en una de las definiciones de mito antes mencionadas. En particular, Bach funge como representante honorario del mito (leyenda de origen significante) que encarna la supuesta superioridad de la música clásica. Bad Bunny es, en cambio, un mito en el segundo sentido (creencia falsa), en cuanto funge como la cara visible del reggaetón, que se encuentra en oposición a cierta conducta ética, aspiración de un sector conservador de la sociedad, el cual ve con preocupación al conjunto de letras e imágenes que el reggaetón promueve, por su potencial injerencia en una conducta sexual precoz y agresiva. 


\section{Bad Bunny y el mito falso del reggaetón malo}

La falsedad que hay en el mito del reggaetón malo no es un asunto que comprometa la integridad moral de quien lo refuerce. El problema radica en la relación de causalidad directa que hace el mito entre el reggaetón y una conducta ética reprochable. Es consabido que reflexiones en torno al machismo, feminismo, asimetrías y violencias de género, hacen compromisos con temas complejos y profundos. Tanto en debates académicos como en conversaciones coloquiales, se hace manifiesto que atender a estas problemáticas está lejos de ser un asunto simple que pueda entenderse en blanco y negro. La urgencia que requiere hablar sobre el machismo en todas sus manifestaciones, habida cuenta del sufrimiento que padecen muchas mujeres, choca entonces con la enorme profundidad que tiene el tema, ya que no es un asunto que pueda resolverse en unas pocas líneas. En las discusiones sobre machismo coexisten factores de la biología evolutiva con prácticas culturales cambiantes, junto a imaginarios social e históricamente construidos, así como revisiones críticas a los niveles de susceptibilidad en la población.

El mito del reggaetón malo es falaz porque suprime toda esa red de factores y matices, reduciendo el problema (real y urgente) del machismo a una relación de causalidad única: la juventud daña su compás ético por consumir esa música. Carretero (2006) apunta a que las creaciones míticas "son recursos culturales íntimamente ligados a la necesidad antropológica de edificar universos simbólicos destinados a clausurar las preguntas acerca de las ultimidades que afectan constantemente a la vida humana" (p. 108). En este caso, la pregunta fundamental que está siendo clausurada, la que ocupa nuestras preocupaciones, es aquella que interroga por las acciones necesarias para disminuir la violencia de género.

En ese sentido, es habitual encontrar situaciones en las que se haga necesario definir algunos conceptos para poder reflexionar sobre el lugar 
que pueda ocupar el reggaetón en problemáticas reales y urgentes para nuestra sociedad. ¿Qué es el acoso sexual? Circunscribiendo la discusión al contexto social-cultural (no al ámbito jurídico-penal), es muy fácil notar que no es una pregunta fácil de contestar. $\mathrm{El}$ mito que se ha construido alrededor del reggaetón instaura artificialmente un orden sobre el escenario caótico que se desprende de la pregunta; una vez instaurado el mito, se evade la presión por analizar críticamente el problema, por atender a sus grises, siendo este análisis reemplazado por una máxima simple pero mítica y equivocada:

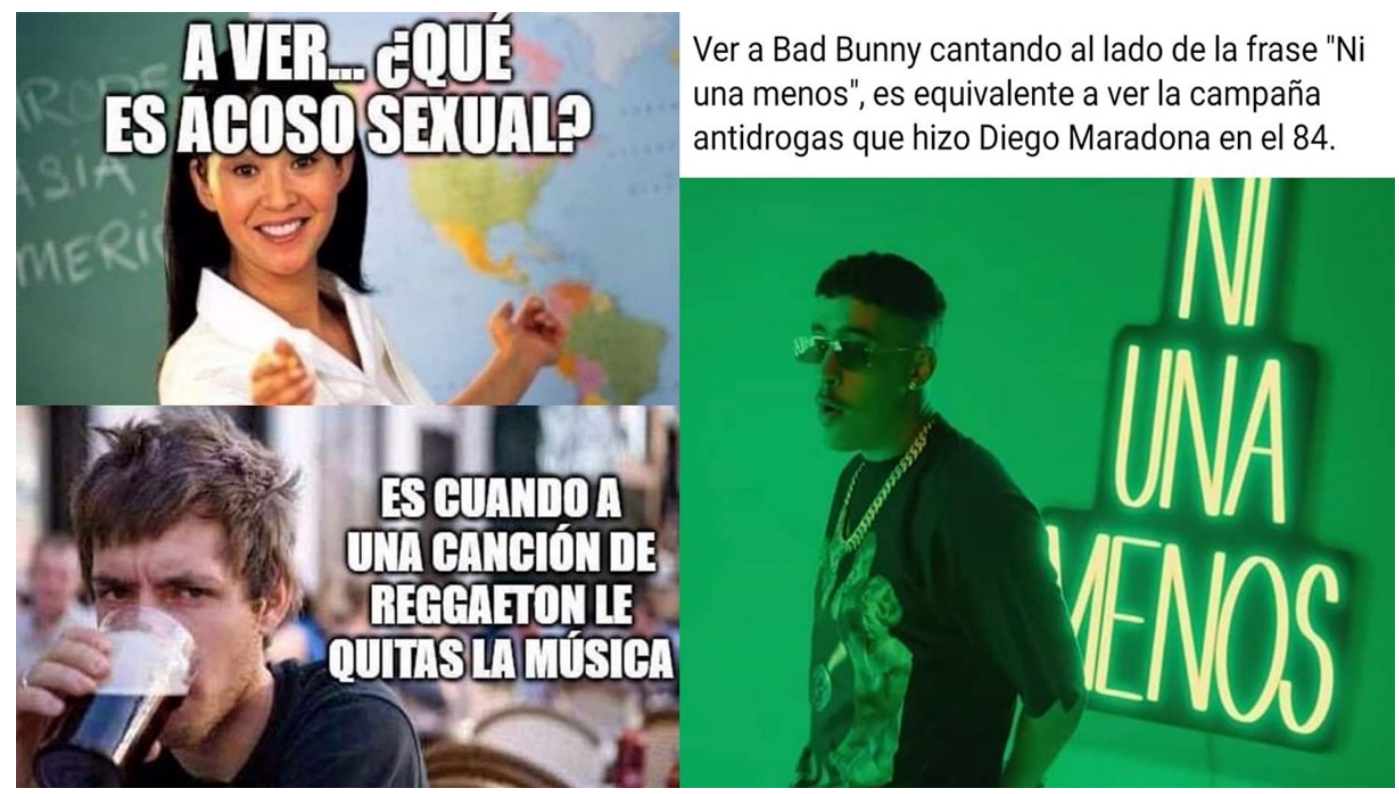

Figura 1. Sobresimplificación de un problema social.

Fuente: @9GAG (22 de junio de 2020), Pinterest; @MemesConciertosMX (29 de marzo 2020), Facebook.

Una revisión superficial del problema en torno al acoso sexual deja ver que nunca es tan simple como parece. Evidentemente, si la discusión se posa en un caso particular, aquello que debería gobernar el debate es el estado físico y mental de la persona acosada, pero si se trata de abordar el fenómeno como una problemática social más amplia, es muy difícil 
establecer una causalidad directa desde las letras o los bailes de cierto artista o de cierto género musical. Aquí resuena lo dicho por Barthes en Mitologías: "el mito realiza una economía de inteligencia: comprende lo real con menos gasto" (Barthes, 1999, p. 136); aquí se comprende lo real como la problemática social, y la economía de inteligencia acusar al reggaetón de causarla. Atender a la relación entre la música y las desigualdades de género evitando una economía de inteligencia, remite a revisar varios frentes, en particular uno en el que las visiones que comprometen la integridad femenina están lejos de ser novedad o exclusividad del reggaetón.

Las prácticas musicales del pasado no son, en ninguna medida, ejemplos de equidad de género ni de respeto por el género femenino. La lista de mujeres que resultan cruelmente asesinadas o que tienen que suicidarse para resolver la trama en favor del hombre, es una lista larguísima en las óperas compuestas desde inicios del siglo XVII. Leonora (La fuerza del destino), Lucía (Lucía de Lamermoor), Tosca (Tosca), Norma (Norma), Lui (Turandot), Isolda (Tristan e Isolda), Leonora (Il Trovatore), Gilda (Rigoletto), Dido (Dido y Aeneas), Carmen (Carmen), y muchísimas otras más, se entregan como sacrificio involuntario o bajo muchas presiones en virtud de reforzar un tropo narrativo en el que la mujer, objeto de deseos y pasiones, es el sufriente silencioso de la trama. El baile vienés que se asocia con los pomposos valses de Strauss hace hincapié en el hombre que domina y escoge pareja en una vitrina social, en la que han sido dispuestas por sus padres las mujeres al cumplir 16 años. Ray Charles canta "Ven y dale amor a tu papi toda la noche. Ella sí sabe cómo moverlo" 5 ; AC/DC pregona "Llévala a ese punto, sabes que ella lo hace muy caliente [...] ella

${ }^{5}$ What I Said: "Come and love your daddy all night long. She knows how to shake that thing" 
es una máquina veloz que mantiene su motor limpio"6; Big Bill entonaba "yo estoy buscando una mujer que no haya sido besada, quizás nos llevemos bien y no tenga que usar mi puño" 7 . La lista de casos similares es muy extensa.

La desmitificación aquí propuesta no está sugiriendo que el uso generalizado de la violencia en las letras de muchas canciones mitiga su connotación negativa. Si fuera cierto que algunas canciones de reggaetón resultan ofensivas para algunas personas, esto no se corrige señalando que otros géneros musicales también lo han sido; por el contrario, implica reconocer la inconsistencia que supone reducir un tema complejo a una relación simple de causalidad mítica: la violencia contra las mujeres no puede explicarse como resultado de las letras de las canciones. Estas pueden integrar la discusión junto a muchos otros productos culturales y de entrenamiento, junto a reflexiones sobre la brecha salarial y el lenguaje incluyente, junto a políticas públicas y dinámicas de educación familiar o escolar; lo que no pueden hacer las letras es acaparar la responsabilidad de haber detonado la conducta que algunas personas puedan tachar de moralmente reprochable, más aún, teniendo en cuenta la diversidad de posiciones sobre ética y moral que coexisten en nuestra sociedad.

El acercamiento poco reflexivo al reggaetón se alimenta también de una posición según la cual el reggaetón es menos música que las demás. Junto a las críticas hechas en torno a las letras, suele apuntarse que el género es menos artístico que los demás, en virtud de sus ritmos monótonos, su extrema simpleza y su condición de producto comercial ${ }^{8}$. Muchas de estas

\footnotetext{
${ }^{6}$ Rock N Roll Train: "Take it to the spot/You know she'll make it really hot". You Shook Me All Night Long: She was a fast machine, she kept her motor clean".

7 When I Been Drinkin: "I'm lookin' for a woman that ain't never been kissed. Maybe we can get along an' I won't have to use my fist".

${ }^{8}$ Dado que es un tema que habita la cultura popular, tales críticas no pueden señalarse directamente a una fuente concreta. Para observar una muestra de estas posiciones críticas hacia el género: El 17 de julio de 2019, la cadena de noticias W Radio, promovió el numeral
} 
posiciones encontraron una vitrina adicional cuando Bad Bunny recibió el premio al Mejor Compositor del Año (2020) de manos de Ascap (Sociedad Americana de Compositores, Autores y Editores, por sus siglas en inglés)9. Diversos medios de comunicación como El Tiempo, La Vanguardia o ABC de España, consideraron que la noticia que merecía ser registrada tenía dos caras: el premio a Bad Bunny y la indignación de millones de personas que consideraban que no lo merecía. La falsedad en algunos de los argumentos deja ver que se está reforzando eficazmente el mito falso del reggaetón malo. Veamos:

- Bad Bunny y el reggaetón son malos por ser demasiado simples (o cualquiera puede hacer eso): La complejidad de una manifestación musical no es algo que transcurra en una sola dirección. Por lo general, señalar al reggaetón de ser simple, en realidad lo que señala es que carece del tipo de complejidad que se encuentra en una Fuga de Bach, por ejemplo. Lo cierto es que (1) no existe una forma única de ser complejo y profundo en la música, y (2) nunca ha podido establecerse que la complejidad musical y la calidad van de la mano. Cabe suponer que géneros musicales como el reggaetón, el bullerengue, la champeta o la cumbia, sí son menos complejos que Bach en algunos parámetros, pero son sin duda mucho más complejos que Bach en otros. La música europea del siglo XVIII es rica y profunda en sus encadenamientos de acordes y la disposición de varias melodías superpuestas unas a otras. Por otro lado, muchos géneros de origen latinoamericano dan cuenta de profundas complejidades en términos rítmicos, y en el caso del reggaetón y otras músicas urbanas, la enorme diversidad de aspectos tímbricos supera por mucho a otras prácticas musicales. De

\#EIReguetónEs, y de los miles de comentarios se hace evidente la tendencia a levantar objeciones frente al reggaetón.

${ }^{9}$ https://www.ascap.com/news-events/awards/2020/latin-awards 
conversaciones con amigos productores de música urbana, resalto sus relatos casi cómicos de músicos jóvenes que llegan al estudio de grabación pensando que sin esfuerzo podrán hacerse una carrera exitosa en el reggaetón. Nunca es así, y no, no cualquiera puede hacer canciones de reggaetón.

- Bad Bunny y el reggaetón son malos por ser solamente un producto comercial (o lo único que les interesa es el dinero): En primer lugar, las características musicales de un disco o una canción, no suelen ser buenas fuentes para descifrar los móviles que acuden a la voluntad del artista. Coexisten muchas razones detrás del lanzamiento de un sencillo. Además, asumir que el factor comercial contamina la producción artística proviene de una visión espiritual de la música, en la que esta baja en forma de musa de un cielo trascendente para posarse sobre la partitura de un compositor inspirado que intermedia entre nosotros los mortales y ese mundo inmaterial de profundidad psicológica. Si bien esa visión de la música y de los músicos gobernó el pensamiento europeo del siglo XIX, está lejos de representar eficazmente el escenario global de la música en el siglo XXI. Cosas parecidas podrían decirse de André Rieu o de Andrea Bocelli, pero no se hacen con el mismo ahínco por no hacer parte de este mito. Por ejemplo, aunque Gioachino Rossini tuvo un éxito comercial considerable con el estreno de El Barbero de Sevilla en 1816, fue hasta el estreno de Guillermo Tell en 1829 que saboreó un éxito financiero significativo. Desde ahí hasta su muerte en 1868 no compuso más óperas (no compuso casi nada más en ningún género) en una especie de jubilación anticipada. La disparidad de criterios con que se critican a Bad Bunny y a Rossini son manifestación del mito falaz que denigra al reggaetón por su interés monetario. 
- Bad Bunny y el reggaetón son malos porque no son arte musical (o eso no puede llamarse música): No solamente no existe una definición monolítica de música, sino que cualquier intento por establecerla está operando violentamente en un marco cultural que quiera acoger principios como la multiculturalidad. Señalar desde la sala de concierto mientras se escucha una cantata de Bach lo que acontece en la discoteca, y reclamar que eso no es música, es el mismo gesto de superioridad que tenían conquistadores al ver la otredad nativa y señalarla de no-cultura. Cerrar la definición de música a una serie de parámetros estrechos formulados por una cultura particular en una época particular, atenta gravemente contra todos los intentos por establecer diálogos interculturales horizontales, separados de la visión colonial y eurocéntrica que, está demostrado, no es la mejor manera en que podemos relacionarnos y comprender el mundo hoy en día.

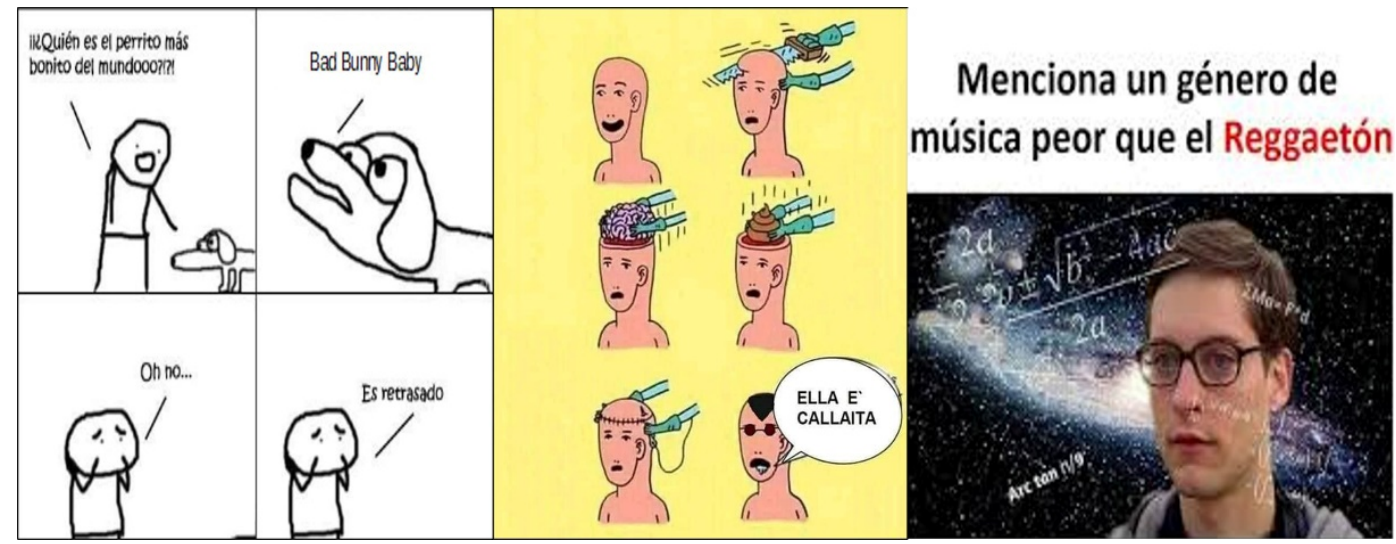

Figura 2. Mitos gráficos del reggaetón malo.

Fuente: @potatto (23 de diciembre de 2016), Memedroid; @EstaWea (5 de enero de 2017), Facebook; @amino (20 de marzo de 2016), Instagram.

Junto a esas manifestaciones del mito se posan otras como la crítica al acento con que Bad Bunny pronuncia la / R/ (¿qué haríamos entonces con Candelario Obeso?), o a la manera en que se viste o maquilla (¿debería usar esmoquin negro?). ¿Qué tienen en común estos tres elementos del 
mito? Están escondiendo una diferenciación de músicas tipo A y de músicas tipo B que refuerzan tensiones poscoloniales de clase social y de estatus cultural. Barthes (1999) aclara este asunto cuando señala que los mitos constituyen manifestaciones exageradas de lo emocional por parte de la burguesía. El sujeto que Barthes usa para explicar es un pequeñoburgués, juntando voluntariamente las dos palabras para indicar la caricaturización de la realidad hecha por medio del mito desde la posición social:

Si lo otro se presenta a su vista, el pequeñoburgués se enceguece, lo ignora y lo niega, o bien lo transforma en él mismo. En el universo pequeñoburgués todos los hechos que se enfrentan son hechos reverberantes, lo otro se reduce a lo mismo. (Barthes, 1999, p. 134)

La otredad que suponen Bad Bunny y el reggaetón, negada o sobre simplificada en la mirada de Barthes, se convierte en mito. Carretero (2006) anota que "el mito procura distanciar al hombre de esta primigenia «angustia vital», consiguiendo racionalizar la inseguridad para transformarla en algo que se torna accesible" (p. 108). La inseguridad detonada por el reggaetón, en la forma de "¿premio al mejor compositor? ¿eso es música?”, se racionaliza en una imagen accesible que responde de forma simplista a esas preguntas: no lo merecía porque eso no es música. 


\section{"El reggaeton es un arte"}

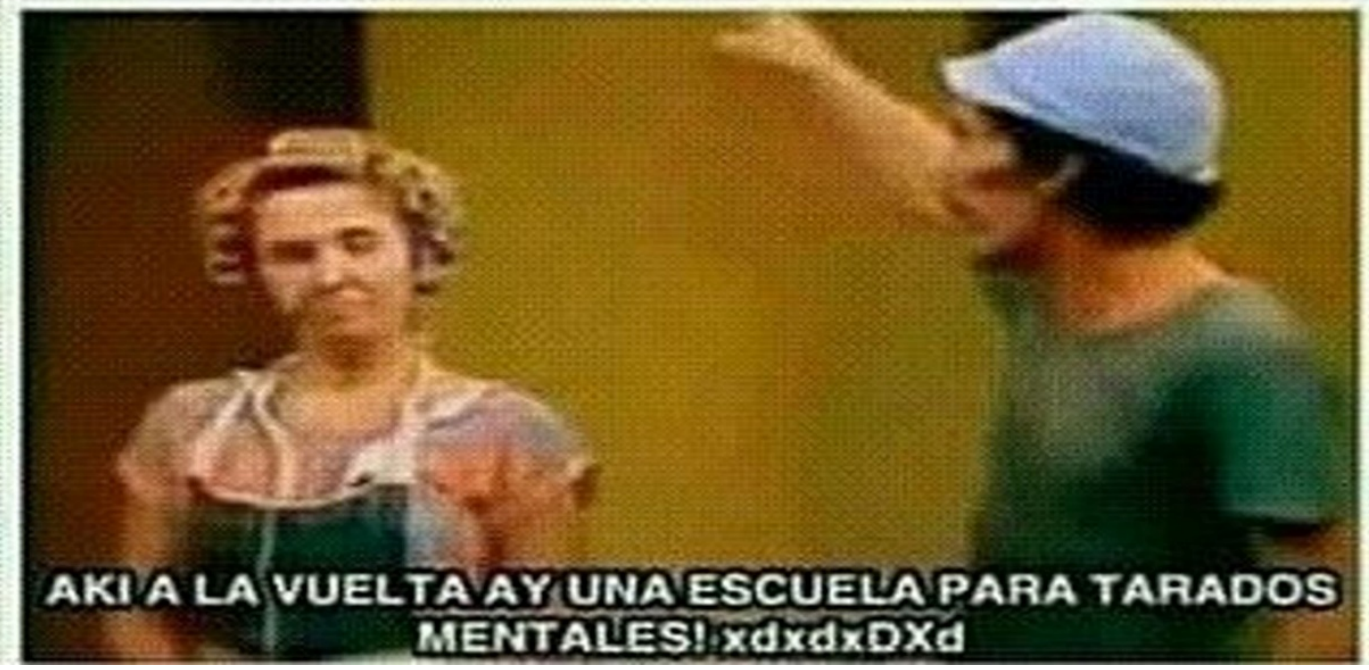

Figura 3. El reggaetón es un arte.

Fuente: @amino (20 de marzo de 2016), Instagram.

\section{Bach y el mito de la música clásica perfecta}

La idea de que exista una música clásica, separada de las demás músicas y que sea digna de ser llamada Arte (con mayúscula y opuesta a la música popular o folklórica), es producto de la historiografía musical del siglo XIX. En siglos anteriores a este, la escritura histórica sobre música y músicos resaltaba las habilidades racionales de los sujetos, o si enlazaba su creación con funciones religiosas, identificaba a los músicos como servidores de la iglesia con su talento y disciplina ${ }^{10}$. La asociación entre el racionalismo laico de la ilustración y la revolución francesa condujo a filósofos e historiadores del siglo XIX a reconsiderar valores cristianos o

\footnotetext{
${ }^{10}$ Warren Allen (1962) profundiza sobre estos procesos.
} 
sobrenaturales para explicar las habilidades particulares de los sujetos notables en la historia. De ahí en adelante son incontables las referencias a los músicos clásicos, con Bach a la cabeza, de vidas separadas del mundo. Músicos que logran proezas increíbles y heroicas, superando los obstáculos que el destino les presenta: sordera, ceguera, pobreza, locura, homosexualidad reprimida, o críticas obtusas, entre otras ${ }^{11}$.

De acuerdo con la visión de Thomas Carlyle (2011) en la que los héroes son el fundamento transversal a toda la historia social, se evidencia que Bach y otros músicos clásicos son excelentes ejemplos de esta perspectiva, en la que el pasado se condensa en un panteón de dioses geniales y creativos. Se ha creado un entorno mitológico en ellos. Eliade (1968) explica que "el mito cuenta cómo, gracias a las hazañas de los Seres Sobrenaturales, una realidad ha venido a la existencia” (p. 7). En particular, el autor señala cinco características del mito vivido por las sociedades arcaicas: (1) constituye la historia de los actos de seres sobrenaturales; (2) la historia se considera Verdadera y Sagrada; (3) se refiere el mito a una "creación", cómo algo ha llegado a la existencia; (4) conocer el mito es conocer el “origen" de las cosas. Conociéndolo se domina y manipula a voluntad el objeto del mito y (5) se vive en el mito. Se está dominado por la potencia sagrada.

La pequeña crónica de Ana Magdalena Bach es una biografía novelada escrita por Esther Meynell (1994) a principios del siglo XX. Su enorme difusión y múltiples ediciones se deben, en parte, a que fue publicada primero de forma anónima y con ello alimentando la idea de ser la voz directa de la segunda esposa de Bach. En la crónica se nos presenta a Bach como portador de unos "ojos oyentes, que tenían a veces un resplandor místico. [...] Nadie podría verle una vez sin volver a mirarle, pues sobre él

\footnotetext{
${ }^{11}$ Ver Wiley (2015).
} 
flotaba algo extraordinario" (Meynell, 1994, p. 14). Músicos altamente influyentes en la vida musical occidental del siglo XIX también aportaron a la construcción de ese Bach místico y sobrenatural. Felix Mendelssohn ha señalado que la "Pasión [según San Mateo] se ha hecho la entrada en la vida pública y se ha vuelto propiedad de las almas”. Max Reger apunta que "Bach es para mí principio y fin de toda música: en él descansa y se basa todo verdadero progreso" (Citados en Boyd, 1986, pp. 217-218). En la perspectiva de Carretero (2006), "la emergencia del mito hunde sus raíces en una dimensión propiamente religiosa" (p. 108), lo cual se manifiesta en las citas antes dispuestas: resplandor místico, algo extraordinario, almas, principio y fin.

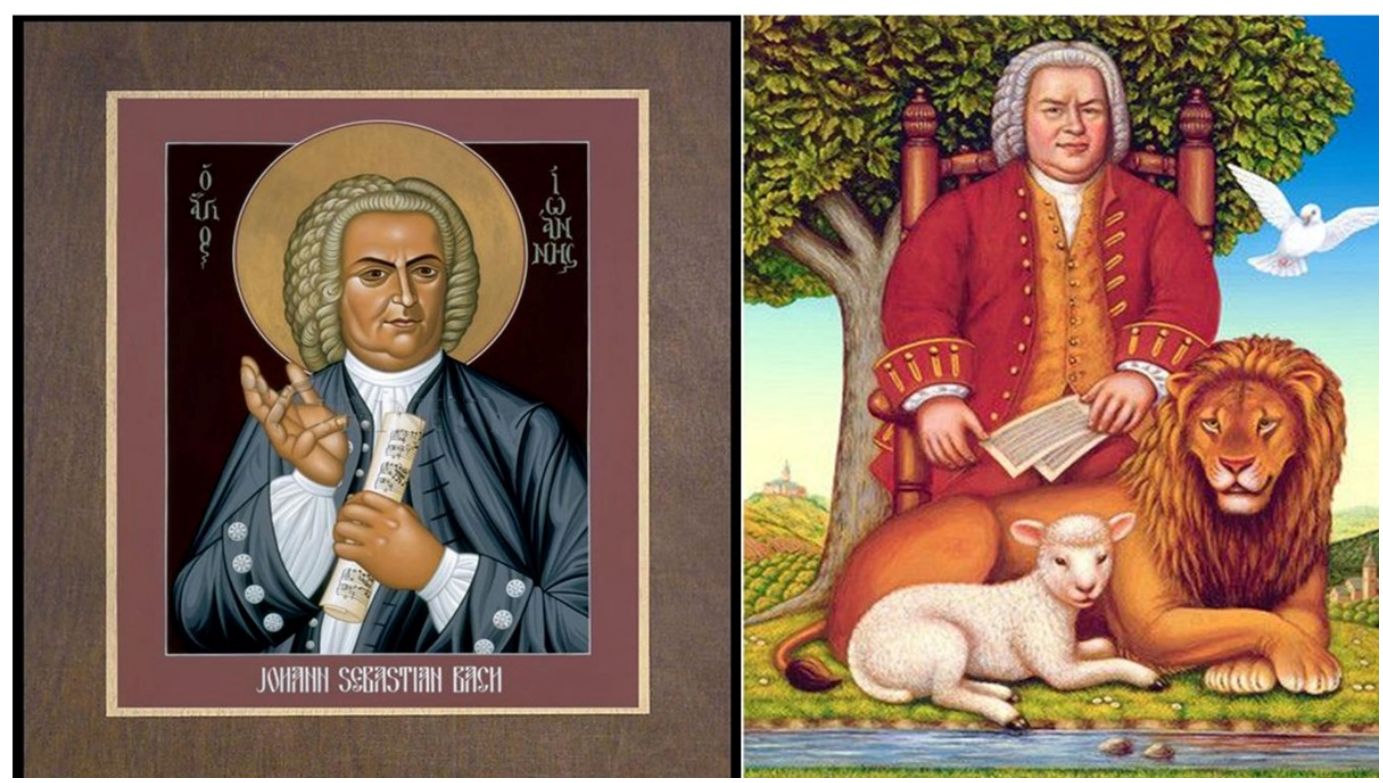

Figura 4. Bach es Dios.

Fuente: Robert Lentz (1946); Frances Broomfield (1951).

Citas como estas no son atípicas, como tampoco es atípico que, en discursos académicos, relatos históricos y el imaginario popular, se asuma que en Bach hay un elemento que se escapa de lo ordinario, se hace sobrenatural (característica 1 en Eliade). La reiteración constante y 
sostenida de este mito hace que se naturalice, se convierta en historia sagrada e incontrovertible (característica 2). Se identifica a Bach como el principio de algo: en las palabras de Beethoven, la música de Bach es "Arte sublime y grandioso del verdadero padre de la armonía" (E.L.B. 1970, p. 6), (características 3 y 4). Se habita en el mito (5) porque la narrativa hace que, no solo Bach sea música, sino que la música sea Bach; Hennion ha llamado la atención sobre esto, identificando que "Bach no se integra en un universo musical preconcebido, lo produce, en parte, por medio de la invención de un nuevo gusto musical” (Hennion, 2003, p. 85).

Vivimos el mito bachiano y estamos dominados por esa potencia sagrada. Cortés (2015) analizó diversos datos en torno a la actividad musical de la sala de conciertos del Banco de la República en Bogotá. De la música ahí interpretada, Bach es el compositor con más apariciones (1220), seguido por Mozart (con 785). Para hacernos una idea de las magnitudes, basta señalar que, en la misma lista, el latinoamericano más presente es VillaLobos con 243 y el colombiano con más recurrencias es Luis A. Calvo con 204. Por otro lado, aunque también sintomático del mismo mito, en el concurso para ser violinista de la Orquesta Filarmónica de Bogotá del 2018, la primera ronda solicitaba explícitamente que se tocaran dos movimientos contrastantes de alguna de las sonatas o partitas de Bach, porque habitando el mito, los jueces del concurso asumen que tocarlo bien equivale a saber interpretar correctamente un texto sagrado, leer sus partituras hace las veces de exégesis.

En el mito bachiano, sin Bach la música no sería lo que es hoy en día. Todos los músicos posteriores le deben devoción. No se debe hablar mal de Bach, no se debe poner en discusión su condición de fuente primigenia del arte musical ni se debe reducir a ser "simplemente" un buen compositor en un espacio-tiempo-contexto determinado. No se debe, ya que un mito "no puede venir más que de la eternidad" (Barthes, 1999, p. 134), porque su 
anclaje "extralimita el orden de lo propiamente racional" (Carretero, 2006, p. 108).

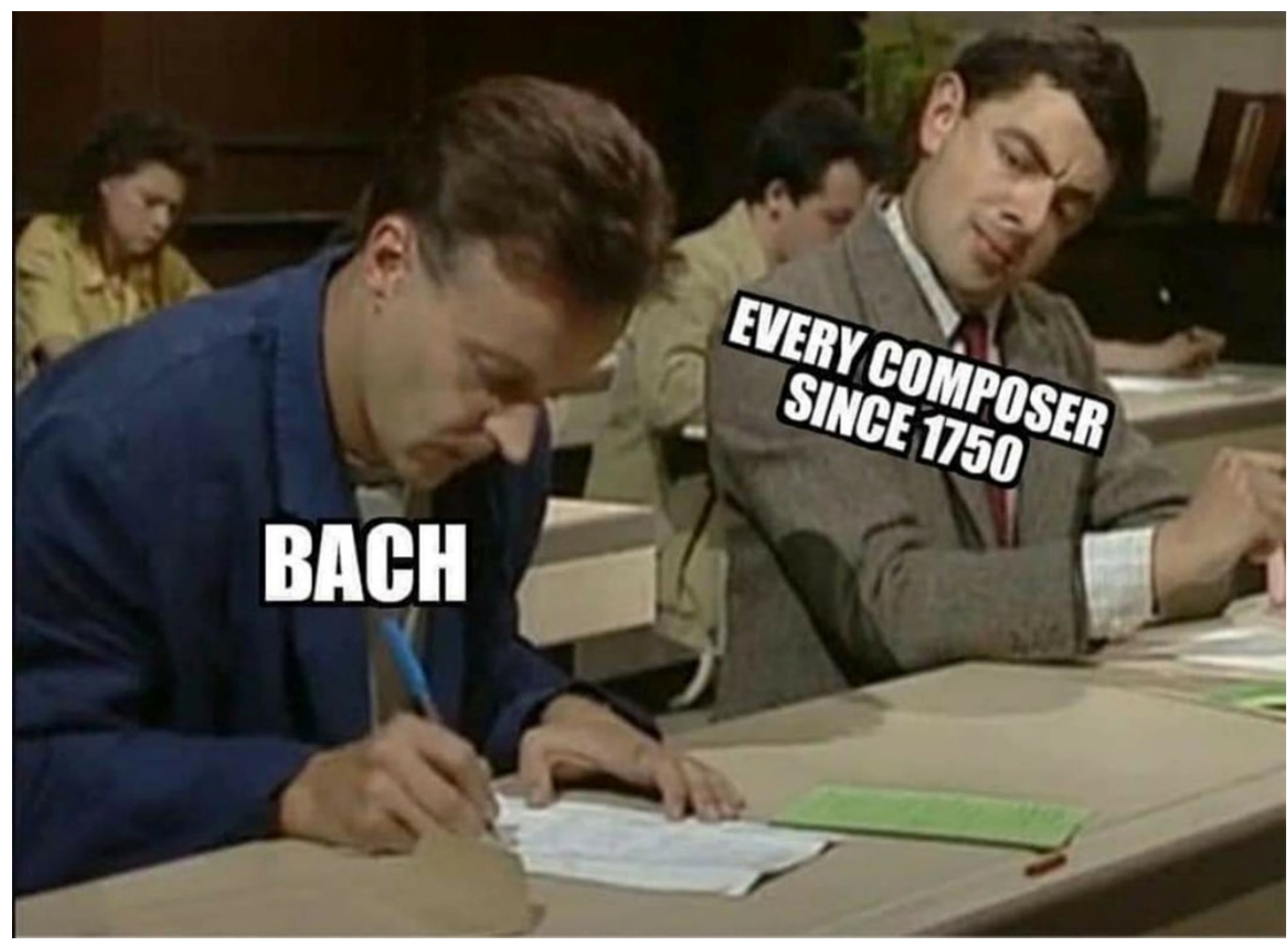

Figura 5. Sin Bach no habría nada más.

Fuente: @Gabriel Mora-Betancur (13 de julio de 2019), Facebook.

\section{Reconectar críticamente los dos mitos}

En realidad, lo que permite al lector consumir inocentemente el mito es que no ve en él un sistema semiológico, sino un sistema inductivo. Allí donde solo existe una equivalencia, el lector ve una especie de proceso causal: el significante y el significado tienen, a sus ojos, relaciones de naturaleza. (Barthes, 1999, p. 121)

El análisis de Barthes explica sintéticamente la existencia de ambos mitos. En una línea similar, Joseph Campbell ha sugerido que contamos historias para tratar de armonizar nuestras vidas con la realidad (p. 28). Nuestra vida y realidad son las palabras claves de esa frase. La necesidad de 
armonizarlas surge de ciertas incompletitudes o ruidos incómodos que emergen de nuestra relación con la música. ¿Qué música trae beneficios o perjuicios a nuestra sociedad? ¿Cómo ha venido esa música a la existencia? Son preguntas profundas de nuestra vida, cosa que se manifiesta en el eco que han encontrado en autores desde Platón hasta nuestros días. La realidad sobre el origen de la música (o de sus características) y sobre el impacto de esta en la sociedad son asuntos sumamente complejos, polifacéticos y reacios a encontrar soluciones definitivas. Por ende, el mito armoniza la vida y la realidad, situando a Bach (y al resto de compositores del canon clásico) como origen de la música y a Bad Bunny (junto a la mayoría de los reggaetoneros) como causante de cierta transgresión a valores morales. Bach y Bad Bunny dejaron de integrar equivalencias y significados para adoptar en el mito la forma de proceso causal, naturalizado.

No se trata de revisar los mitos para suponer una vida sin ellos. Horkheimer y Adorno ya hicieron un diagnóstico acertado al respecto, al establecer que el proyecto de la ilustración sobre la disolución de los mitos y el desencantamiento del mundo fue, al mismo tiempo, un tipo de pensamiento que se hacía violencia a sí mismo (Horkheimer y Adorno, 1998, pp. 59-60). Se hizo violencia porque se usaron mitos para desmontar otros mitos, por lo cual ambos gestos (mitificación y desmitificación) adquirieron forma de doctrina. Lo que sí se reclama en estas líneas es el beneficio potencial de operar críticamente sobre los mitos, por lo que esconden, por lo que veladamente refuerzan o sustituyen.

Fernández Pichel (2010) indica que la creación de mitos contemporáneos se relaciona con la diversidad de figuraciones de la realidad que coexisten en un contexto globalizado. En su análisis, la emergencia masiva de mitos en una sociedad tan anclada en la lógica productiva se explica por medio de la transmisión y reproducción de los mensajes de la cultura audiovisual: 
"el mito, desacralizado, mundano, profano, se reinserta en los discursos asociados a la cultura popular, reclamando de nuevo su estatuto en el terreno de lo real" (Fernández, 2010, p.273). Este proceso no ha ocurrido en el vacío, por el contrario, el mito no puede escapar a maniobras de intencionalidad, como lo hacen todas las narrativas históricas. Desde ahí, los mitos contemporáneos como los de Bach y Bad Bunny son portadores también de posturas ideológicas.

No hay mejor evidencia de esto que la ferocidad con que se han instalado posiciones en una u otra dirección. En el caso del reggaetón, es notable que su mitificación negativa le ha impedido recibir el tratamiento que reciben otros géneros musicales: hay muchas personas a las que les gusta el jazz, y hay otras que no. Por lo general, a quienes no les gusta el jazz, les resulta indiferente que a otros sí les guste y viceversa. Por otro lado, es muy fácil encontrar personas a las que, no solo no les gusta el reggaetón, sino que no les gusta que a otros les guste. Tal situación se puso de manifiesto el 17 de julio de 2019, cuando en la cadena de noticias radiales $L a W$ el tema del día fue \#ElReguetónEs. Como era de esperarse por la amplia difusión de la emisora, innumerables mensajes y comentarios llenaron las redes sociales. Lo que resultó más interesante de la plétora incesante de voces que estaban interviniendo, es que se convirtió muy rápido en una discusión con solo dos opciones, en una falsa dicotomía en la que ambos bandos se atacan con violencia. Como si fuera poco, estos bandos, además, se alinearon rápidamente con polos políticos opuestos. Un usuario señaló que el reggaetón es "el Uribe de la música", cosa que celebraron en ambos equipos porque no era claro si se estaba apoyando o denigrando del género. Para unos fue mitificación positiva (es héroe para unos) y para otros fue mitificación negativa (es villano para otros).

Este fanatismo no descansa únicamente en un gusto musical determinado, requiere de un mito que lo soporte, que legitime y naturalice sus 
significados. Dicho entusiasmo dogmático, además de implicar un deterioro del diálogo amistoso, guarda otro peligro:

El fanatismo por un determinado tipo de música genera también actos discriminatorios contra comunidades musicales opuestas, las cuales son vistas y, lo que es aún peor, tratadas como inferiores a la elegida como propia [...] Me refiero a la alarmante violencia verbal con que hoy en día enfurecidos grupos de fans de una música dada arremeten en las redes sociales contra otras comunidades musicales, [...] como si las divergencias musicales fueran un asunto de tanta envergadura que justificasen desatar una cruzada por el gusto adecuado. (Mendívil, 2016, p. 115)
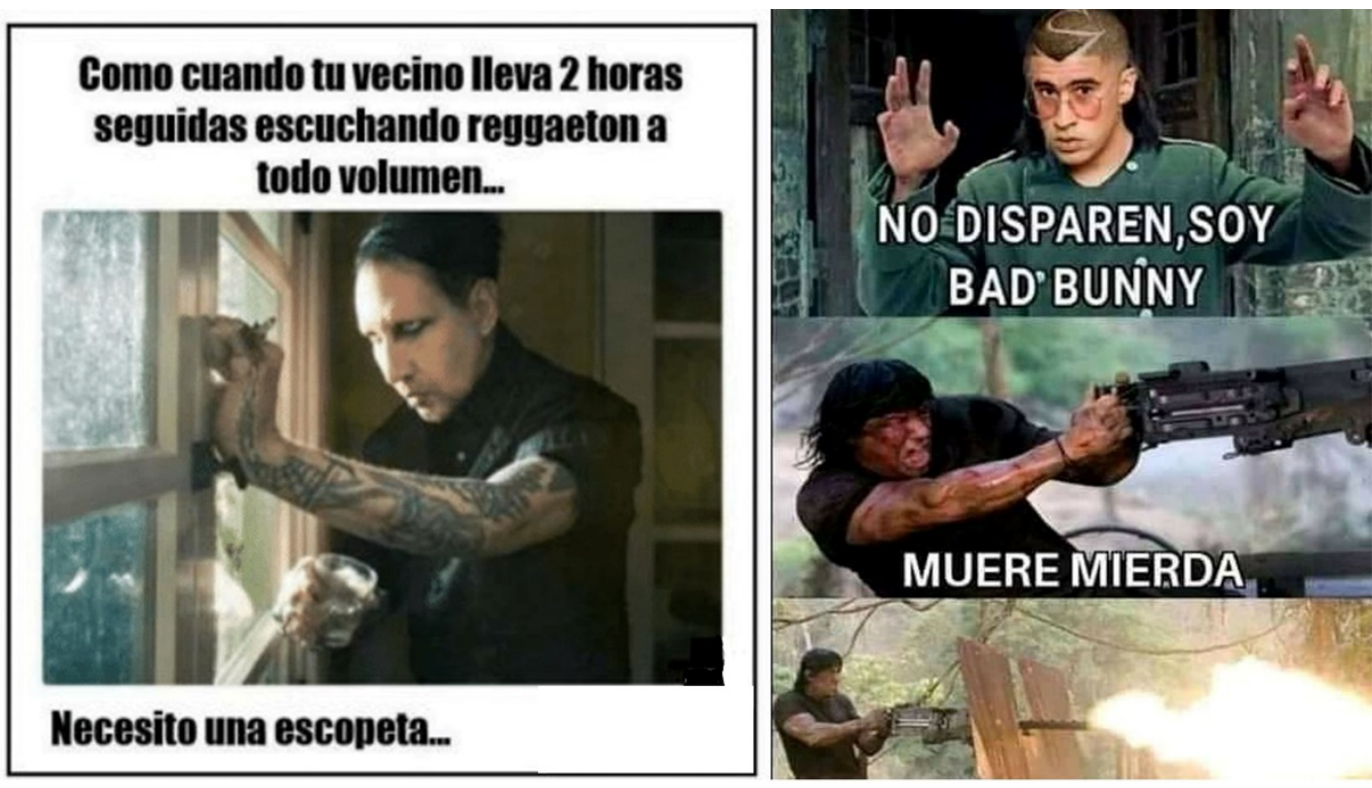

Figura 6. Odiamos al reggaetón.

Fuente: @amino (20 de marzo de 2016), Instagram; @Breve encuentro (10 de maro de 2021), Facebook.

El vínculo entre posiciones radicales en torno a los gustos musicales y relaciones entre comunidades musicales opuestas que resalta Mendívil no es un tema menor. Como bien ha observado Rojas (2009), la construcción de los mitos es inseparable de los ritos y del territorio (geográfico y 
cultural). En ese sentido, mitos que establezcan jerarquías musicales, situando a Bach en un extremo de superioridad artística y a Bad Bunny en el otro, son también mitos que refuerzan dinámicas de exclusión y discriminación. Estas no se ubican al nivel de la voluntad individual de los partícipes: no se es excluyente o discriminatorio automáticamente por tener gustos definidos frente a determinada música. Pero quienes ya participan de una mirada poscolonial de la cultura latina, quienes pretendan defender la universalidad de una música clásica-europea superior a todas las demás, encontraran en los dos mitos un argumento muy poderoso. Estos ofrecen una tribuna desde la cual la superioridad moral y estética de una música sobre otra es sintomática de la superioridad de una tradición cultural sobre otra, y por ende legitiman relaciones asimétricas de poder. Se reconoce en el reggaetón una expresión de la identidad cultural latinoamericana (Marshall, 2010) y se reconoce también la música clásica como manifestación socialmente construida en Europa central (Shepherd, 2003), pero al mismo tiempo se enmarcan ambas músicas en una mitología que las cualifica, las jerarquiza y las somete a revisiones fanáticas e injustificadas - pero naturalizadas-, y se termina incurriendo en jerarquizar también ambas tradiciones culturales en una balanza que no le hace justicia a ninguna de las dos.

Es un hecho que muchas músicas latinoamericanas no se han alineado con el estándar moral de algunos sectores de la sociedad. En esa disyuntiva, operan asuntos generacionales y de clase social. Generacionales porque en una especie de constante histórica, es bastante usual que personas mayores de cuarenta años vean como una amenaza a los "valores tradicionales" la música de los jóvenes. Ejemplos de esto son visibles en abundancia desde la bula del papa Juan XXII en el año 1322 en la que reniega el deterioro de cierta "nueva música" en términos que, solo cambiando algunas variables, encajan perfectamente en la crítica feroz que 
recibe el reggaetón hoy en día: "Ciertos discípulos de una nueva escuela hacen música incorrecta [...], desprecian los principios tradicionales [...], inundan su canto con vulgaridades [...], embriagan los oídos y no se preocupan por el espíritu" (Citado en Fubini, 2005, p. 123 ). Algunos aspectos de clase social intervienen en la medida en que el reggaetón está enlazado con un origen popular en El Barrio; una categoría social de alta influencia en Panamá y Puerto Rico (Samponaro, 2009). Los orígenes del reggaetón guardan como sello distintivo la asociación con la pertenencia a esta categoría. El Barrio representa en sus letras, videos, vestuarios y otros signos, un sentido de pertenencia a un grupo cultural que se define por sus carencias socioeconómicas, cuya marca notable es la diferencia frente a otras clases sociales. En ese sentido, es tan provocador como desmitificador el título del disco de Daddy Yankee El Barrio Fino (2004), porque combina dos términos aparentemente contradictorios, asunto explicado en una especie de manifiesto que encabeza el disco.

Nací entre calles oscuras nací en donde vivo.

Nací en donde sin duda

para mucha gente está prohibido.

Lo llamo barrio con orgullo

lo llaman barrio los de afuera.

Y el honor por nacer aquí

me lo atribuyo.

Yo que soy quien soy a mi manera de barrio

pero de Barrio Fino. 


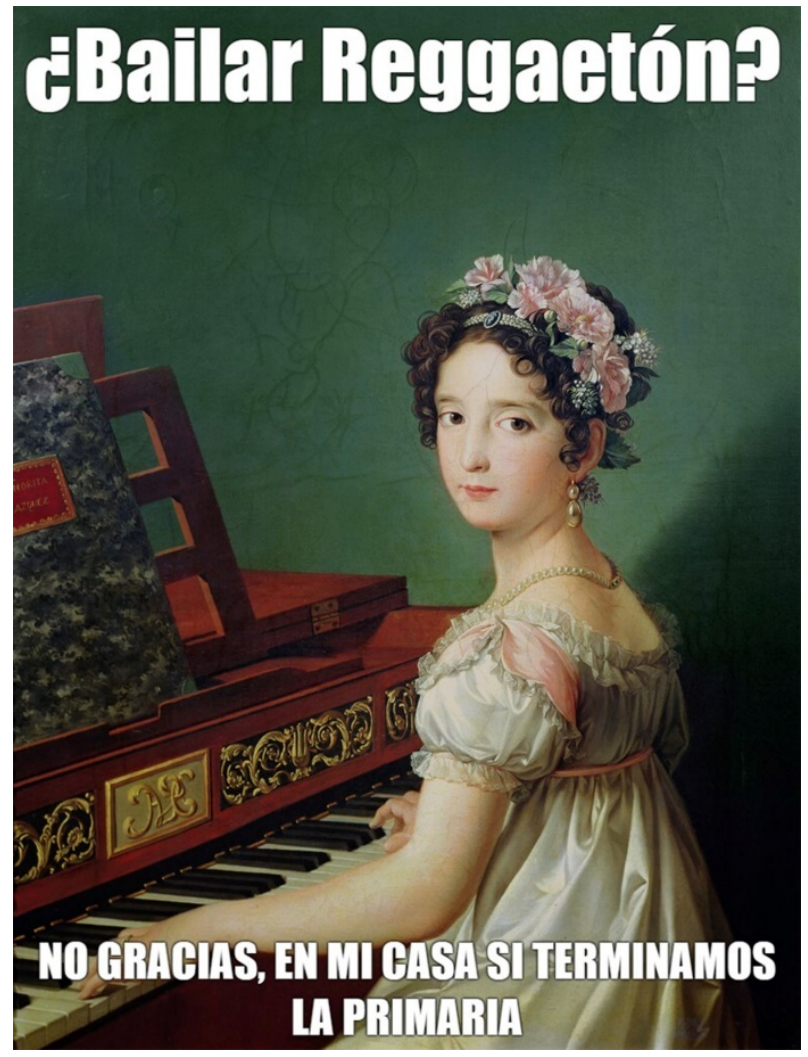

Figura 7. No bailo reggaetón.

Fuente: @awwmemes (9 de junio de 2019), Pinterest.

En la figura 7 se ve a Manuela Gonzáles Velázquez, hija del pintor español Zacarías González, quien le hizo ese retrato en 1820. El meme no es solamente un chiste inocente, por el contrario, acoge y refuerza una serie de mitos. Si bien la imagen anuncia con sarcasmo que bastó con terminar la primaria para notar que el reggaetón no merece ser bailado, el mismo mensaje hubiera podido formularse sin la imagen de Manuela. El aporte al mensaje provisto por la pintura de fondo es peligrosísimo, pues ahí se hace manifiesto el acople eficaz entre música y discriminación de clase social. Manuela reniega del reggaetón sentada en un clavicordio (instrumento simbólico de la tradición clásica europea, que Bach conoció al final de su vida), sentada frente a un libro de partituras (evidencia de una forma particular de práctica musical), con atuendo y tocando; estas imágenes dan 
cuenta de la clase a la que pertenece. Cabe pensar que en el meme es la clase alta latinoamericana que, pensando que con ello imita mejor a la cultura europea, vincula su posición y su educación escolar con la música clásica, desdeñando, por ende, lo pretendidamente inculto del perreo. Como los dos mitos se ven ahí enmarcados en una broma, tal condición permite que se le limpie del clasismo agresivo que promueve. Si la crítica al reggaetón se alimenta de visiones tan radicales, es entendible que se cree una brecha entre los músicos que alientan el género y sus detractores, que frecuentemente son defensores de la música clásica como aporte fundamental a la cultura.

Sin ninguna duda, el problema no está en que unas personas tengan unos gustos y otras se inclinen por otros, el problema emerge al considerar la posibilidad de que la cercanía con un género musical se integre en un escenario donde tenga lugar la exclusión social o el esnobismo en la apreciación musical. Como se ha señalado anteriormente, establecer una jerarquía de calidad entre géneros musicales que pueda servir como argumento que sirva para discriminar también grupos sociales responde a una estrategia indefendible e inconsistente. En materia de cualidades artísticas, conviene adoptar cierto relativismo en el que estas sean evaluadas atendiendo a los parámetros particulares de cada género. Así entonces, las bondades que pueda tener la música de Bach no son eficaces en tanto marco para atender a las dinámicas propias de Bad Bunny. Ignorar este hecho no solo guarda el peligro de dotar nuestra apreciación musical de cierto esnobismo, sino de reforzar implícitamente discriminaciones de clase social.

Cabe suponer que, en la estructura de ambos mitos está otro mito ejerciendo alguna presión, uno que establece que la participación en una actividad musical es altamente influyente en la configuración de nuestros comportamientos sociales. Entender las razones que conducen a que un 
conjunto de personas se comporte de una manera u otra conduce a una red de influencias que sobrepasan por mucho las intenciones de este texto; no obstante, sí conviene resaltar que el poder ejercido por la música en la sociedad corre el riesgo de mitificarse también, exagerando sus resultados de manera un tanto simplista. Intentos por establecer relaciones de causalidad entre la música escuchada y la configuración de la sociedad pueden rastrearse hasta pensadores como Platón y Aristóteles, sin embargo, tal ejercicio de asociación directa nunca ha podido encontrar una respuesta satisfactoria o definitiva. Por el contrario, si algo caracteriza la musicología de las últimas décadas es el reconocimiento de que en la relación música-cultura, nunca es solo la melodía, la armonía o la letra las que intervienen, sino que las experiencias musicales se alimentan de múltiples entradas, contextos y expectativas. Por cierto, si se indicara que es la adhesión a cierta música la que configura la conducta pacífica o violenta, recatada o impúdica, podría estarse incurriendo en desviar la atención sobre razones más plausibles, pero más complejas que explican el fenómeno.

En ese marco, una desmitificación reflexiva de estos mitos tiene beneficios potenciales. Situar la música de Bach en un entorno más humano, sin la carga del símbolo genial y sobrenatural, puede enriquecer la experiencia suscitada por su música. La ubica en tanto manifestación artística que, sin ser tildada de universal ni imprescindible, responde a la perseverancia y el talento de sujetos diligentes en su oficio, al tiempo que reconoce la importancia de observar cómo un contexto de patrocinio al artista desde la oficialidad gubernamental despierta una producción artística abundante y de calidad. Por otro lado, desmontar el mito del reggaetón promueve la apreciación de sus bondades artísticas, del lugar que ocupa en la formación de una identidad latinoamericana y de la red de relaciones que 
está tejiendo con otros géneros musicales, dando paso a nuevos ritmos y géneros musicales que están aún en etapas germinales.

Adicionalmente, desmitificar al reggaetón permite una discusión más honesta y tranquila sobre la conducta moral que se espera de la sociedad. Si quisiera establecerse una conversación sobre la directriz ética de la sociedad, si se considerara necesario abordar un debate sobre lo que significa una sexualidad responsable, y si, al mismo tiempo, se planteara la posibilidad de integrar en la discusión las preferencias musicales de los jóvenes, teniendo en cuenta que estas pueden participar en la construcción de imaginarios sociales sobre lo femenino y lo masculino, no tiene provecho alguno señalar con el dedo a ciertos géneros musicales como causantes únicos de un deterioro moral que, de por sí, es difuso y abstracto.

\section{Referencias}

Allen, W. D. (1962). Philosophies of music history. Dover.

Ardila, H. (2009). Johann Sebastian Bach y el Disteismo. Giordano Bruno Editores y Ediciones Veramar.

Asimov, I. (1981). Las palabras y los mitos. Laia.

Barthes, R. (1999). Mitologías (12. ${ }^{\mathrm{a}}$ ed.). Siglo XXI Editores.

Becker, J. (1986). Is Western Art Music Superior? The Musical Quarterly, 72(3), 341-359

Boyd, M. (1986). Bach. Salvat.

Bueno, G. (2008). El mito de la derecha. Temas de Hoy.

Campbell, J. (1991). El poder del mito. Emecé editores.

Carlyle, T. (2011). On Heroes, Hero-Worship, and the Heroic in History. Barnes y Noble.

Carretero, A. (2006). La persistencia del mito y de lo imaginario en la cultura contemporánea. Política y Sociedad, 43(2), 107-126. 
Clark, S. y Rehding, A. (eds.). (2001). Music theory and natural order from the Renaissance to the early twentieth century. Cambridge University Press.

Cortés, J. (2015). 50 años de programación musical de la Sala de Conciertos de la Biblioteca Luis Ángel Arango. En Si las paredes hablaran: 50 años de música en la Biblioteca Luis Ángel Arango. (pp. 102-132). Banco de la República.

Daddy Y. (2004). El Barrio Fino (CD audio). El Cartel Records. Universal Music Latino.

De Toro, X. (2011). Métele con candela pa' que todas las gatas se muevan. Identidades de género, cuerpo y sexualidad en el reggaetón. Revista Punto Género, 1, 81-102.

E.L.B. (1970). Beethoven on Bach: Excerpts from Letters. Bach, 6-8.

Eliade, M. (1968). Mito y realidad. Guadarrama.

Fernández, S. (2010). Mitos e imaginarios colectivos. FRAME, 6, 265-284.

Fubini, E. (2005). La estética musical desde la Antigüedad hasta el siglo XX (2. ${ }^{\mathrm{a}} \mathrm{ed}$.). Alianza.

Hennion, A. (2003). Music and Mediation: Toward a New sociology of Music. En M. Clayton, T. Herbert y R. Middleton. (Eds). The Cultural Study of Music. (pp. 79-90). Routledge.

Horkheimer, M. y Adorno, T. (1998) Dialéctica de la Ilustración (3. ${ }^{\mathrm{a}}$ ed.). Trotta.

López Cano, R. (2000). Música y Retórica en el Barroco. Universidad Nacional Autónoma de México.

Marshall, W., Rivera, R. y Pacini, D. (2010). Los circuitos socio-sónicos del reggaetón. Trans. Revista Transcultural de Música, (14), 1-9.

Martínez, D. (2014). Música, imagen y sexualidad: el reggaetón y las asimetrías de género. El cotidiano, 186, 63-67.

Mendívil, J. (2016). En contra de la música. Herramientas para pensar, comprender y vivir las músicas. Gourmet Musical.

Meynell, E. (1994). La pequeña crónica de Ana Magdalena Bach. Editorial Juventud.

Pedrosa, D. (2012) El efecto Bach como estrategia que contribuye al liderazgo y la creatividad. Dimensión Empresarial, 10(1), 78-86.

Penagos, Y. (2012). Lenguajes del poder. la música reggaetón y su influencia en el estilo de vida de los estudiantes. Plumilla educativa, 10(2), 290-305.

Análisis

ISSN: 0120-8454 | e-ISSN: 2145-9169 | DOI: https://doi.org/10.15332/21459169

Vol. 53 N.o 99 | julio-diciembre de 2021 
Restall, M. (2004). Los siete mitos de la conquista española. Paidós.

Rojas, J. (2009). Mito, rito y territorio: un modelo para entender la regulación en y entre los sistemas culturales. Análisis, 74, 53-70.

Samponaro, P. (2009). “Oye mi canto" ("Listen to My Song”): The History and Politics of Reggaetón. Popular Music and Society, 32(4), 489-506.

Shepherd, J. (2003). Music and Social Categories. En M. Clayton, T. Herbert y R. Middleton. (eds.). The Cultural Study of Music (pp. 68-78). Routledge

Tepper, J. (2020). El mito del capitalismo: Los monopolios y la muerte de la competencia. Roca Editorial.

Wiley, C. (2015). Musical Biography and the Myth of the Muse. En V. Kurkela y M. Mantere. (Eds.). Critical Music Historiography: Probing Canons, Ideologies and Institutions (pp. 251-262). Routledge. 